\title{
JUKMAS
}

Jurnal Untuk Masyarakat Sehat (JUKMAS)

e-ISSN : 2715-7687

Vol. 4, No. 1 April 2020

P-ISSN : 2715-8748

\section{Prediktor Faktor Lingkungan Sosial untuk Kualitas Hidup Lansia di Wilayah Rural dan Urban}

\author{
Susiana Nugraha ${ }^{1}$, Dinni Agustin ${ }^{2}$ \\ ${ }^{1}$ Program Studi Kesehatan Masyarakat, Fakultas IImu Kesehatan \\ Universitas Respati Indonesia \\ ${ }^{2}$ Program Studi Ilmu Administrasi Niaga, Fakultas Manajemen dan Bisnis, \\ Universitas Respati Indonesia \\ Email : susiana.nugraha@gmail.com
}

\begin{abstract}
ABSTRAK
Perubahan fisik yang terjadi pada Lansia erat kaitannya dengan perubahan psikososialnya. Pengaruh yang muncul akibat berbagai perubahan pada lansia tersebut jika tidak teratasi dengan baik, cenderung akan mempengaruhi kesehatan lansia secara menyeluruh dan mempengaruhi kualitas hidupnya. Penelitian ini ditujukan untuk mengetahui prediktor kualitas hidup lansia di wilayah rural dan urban di wilayah Kota Cimahi. Hasil penelitian menunjukkan bahwa wilayah Rural yaitu rata - rata umur lansia 69,10 tahun dan di Urban 69,07 skor, untuk wilayah Rural yaitu rata - rata dukungan sosial 42,60 skor dan di Urban 42,60 skor, untuk wilayah Rural yaitu rata - rata fungsi keluarga 12,73 skor dan di Urban 12,46 skor, untuk wilayah Rural yaitu rata - rata keterlibatan lansia di masyarakat 10,85 skor dan di Urban 11,51 skor. Hasil analisis pada pemodelan multivariat menunjukkan bahwa model hanya sesuai dan signifikan untuk lansia yang tinggal di wilayah urban dengan nilai $R^{2}=0,17$ dan $p$ value $=0.014$. Temuan dalam penelitian ini berimplikasi pada pentingnya memperhatikan faktor fungsi keluarga yang yang berada di rumahnya yang dapat mempengaruhi kualitas hidup lansia sehingga di harapkan agar lansia melewati hari - hari dalam hidupnya dengan kualitas hidup yang semakin baik.
\end{abstract}

Kata kunci: kualitas hidup, lansia, rural, urban

\begin{abstract}
Physical changes among in the elderly are closely related to psychosocial changes. The effects that arise due to various changes in the elderly, tend to affect the overall health of the elderly and affect the quality of life. This study aimed to determine the predictors of the quality of life of the elderly in rural and poor areas. The results showed that the Rural area is the average age of the elderly 69.10 years and in the Urban 69.07 score, for the Rural area the average social support is 42.60 and in the Urban 42.60 score, for the Rural area that is average - average family function 12.73 score and in Urban 12.46 score, for the Rural area which is the average involvement of the elderly in the community 10.85 score and in Urban 11.51 score. The results of the analysis on multivariate modeling showed that model is not suitable for elderly living in rural area. While for the elderly living
\end{abstract}


in urban area the selected variabel model is significantly affecting their quality of life with $R^{2}=17 \% p=0.014$. The implications of this finding is to consider importance of paying attention to the functioning factors of families in their homes that can affect the quality of life of the elderly so that it is expected that the elderly pass through the days of their lives with a better quality of life.

Keywords : quality of life, elderly, rural, urban

\section{PENDAHULUAN}

Kemajuan ilmu pengetahuan dan teknologi serta perbaikan sosial ekonomi berdampak pada peningkatan derajat kesehatan masyarakat dan usia harapan hidup, sehingga jumlah populasi Lansia juga meningkat. Sampai sekarang ini, penduduk di 11 negara anggota World Health Organization (WHO) kawasan Asia Tenggara yang berusia di atas 60 tahun berjumlah 142 juta orang dan diperkirakan akan terus meningkat hingga 3 kali lipat di tahun 2050 (1).

Populasi lansia di Indonesia sendiri pada tahun 2020 sekitar 80.000.000lansia. Jumlah Lansia di Provinsi Jawa Barat saat ini mencapai 9.064.810 jiwa (2). Pada abad ke-21 tantangan khusus bidang kesehatan dari terus meningkatnya jumlah Lansia yaitu timbulnya masalah degeneratif dan penyakit tidak menular (PTM) seperti diabetes, hipertensi, dan gangguan-gangguan kesehatan jiwa yaitu depresi, demensia, gangguan cemas, dan sulit tidur (3). Penyakit-penyakit tersebut, akan menimbulkan permasalahan jika tidak diatasi atau tidak dilakukan pencegahan, karena ini akan menjadi

penyakit yang bersifat kronis dan multi patologis yang akan mempengaruhi kualitas hidup lansia (4)

World Health Organization mendefinisikan kualitas hidup sebagai persepsi individu terhadap kehidupannya di masyarakat dalam konteks budaya dan sistem nilai yang ada yang terkait dengan tujuan, harapan, standar, dan perhatian.Kualitas hidup merupakan suatu konsep yang sangat luas yang dipengaruhi kondisi fisik individu, psikologis, tingkat kemandirian, serta hubungan individu dengan lingkungan (4)

Warga lanjut usia menghadapi kelemahan, keterbatasan dan ketidakmampuan, sehingga kualitas hidup pada lanjut usia menjadi menurun. Faktor yang mempengaruhi kualitas hidup lansia adalah lingkungan fisik, kebijakan lingkungan dan lingkungan sosial dimana lingkungan sosial ini mencakup dukungan sosial, fungsi keluarga dan keterlibatan 
lansia di masyarakat. Keluarga memiliki peran yang sangat penting dalam perawatan lanjut usia untuk meningkatkan kualitas hidup lanjut usia. $(5,6) 7)$.

Keluarga merupakan unit terkecil dari masyarakat sehingga memiliki peran yang sangat penting dalam dukungan maupun perawatan lanjut usia untuk meningkatkan kualitas hidup lanjut usia Interaksi sosial atau dukungan sosial dalam keluarga dapat berjalan dengan baik apabila keluarga menjalankan fungsi keluarga dengan baik, terutama dalam fungsi pokok kemitraan (partnership), kasih sayang (affection), dan kebersamaan/resolve $(8)(6,9)$

Dukungan sosial dapat mempengaruhi keseharian Lansia, dimana dukungan ini bisa berasal dari segala sesuatu yang terdapat di sekitar manusia yang dapat memberikan pengaruh pada manusia tersebut, serta manusia-manusia lain yang ada di sekitarnya, seperti tetangga, teman-teman, bahkan juga orang lain di sekitarnya yang belum dikenal sekalipun , demikian juga dengan dukungan dari masyarakat sekitar yang turut mempengaruhi keikutsertaan lanjut usia dalam kegiatan yang berlangsung disekitar tempat tinggalnya $(7,10)$. Lingkungan tempat tinggal menjadi faktor penting yang berpengaruh terhadap kualitas hidup lansia. Lingkungan tempat tinggal yang berbeda mengakibatkan perubahan peran lansia dalam menyesuaikan diri.Agar kualitas hidup lansia meningkat, maka dalam penyesuaian diri dan penerimaan segala perubahan yang dialami, lansia harus mampu beradaptasi dengan lingkungannya. Lingkungan yang memahami kebutuhan dan kondisi psikologis lansia membuat lansia merasa dihargai. Tersedianya media atau sarana bagi lansia membuat lansia dapat mengembangkan potensi yang dimiliki.

Perbedaan tempat tinggal dapat menyebabkan munculnya perbedaan lingkungan fisik, sosial, ekonomi, psikologis dan spiritual lansia yang dapat berpengaruh terhadap status kesehatan penduduk usia lanjut yang tinggal di dalamnya. Permasalahan yang mendasari baik dan buruknya derajat kesehatan lansia ialah dari lingkungan tempat tinggal mereka (11)

Jumlah penduduk yang tinggal di perdesaan Indonesia sebesar 7,63\% (12). Di Jawa Barat khususnya di Cisarua Kabupaten Bandung Barat terdapat Puskesmas Pasir Langu dimana kebanyakan masyarakatnya mencari nafkah dengan cara bercocok tanam 
sebagaimana salah satu ciri dari kehidupan di perdesaan. Puskesmas Pasir Langu memiliki posyandu aktif dengan jumlah Lansia sebanyak 3.194 orang.

Jumlah penduduk Lansia yang tinggal di perkotaan Indonesia sebesar 7,49\% (4). Di Jawa Barat khususnya Kota Cimahi terdapat Puskesmas yang memiliki program Posbindu aktif dan program Gerakan Hidup Sehat Lansia yaitu Puskesmas Cimahi Tengah dimana program ini diperuntukan bagi lansia agar tetap aktif di lingkungan sosial, peningkatan akses kesehatan dan kualitas pelayanan, dan pemberdayaan keluarga dalam pembinaan lansia. Jumlah Lansia di wilayah kerja Puskesmas Cimahi Tengah yaitu 2.052 orang.

Pada tahun 2012 selisih jumlah lansia di perdesaan dan perkotaan yaitu 0,14\% dimana penduduk lansia lebih banyak tinggal di perdesaan daripada di perkotaan (Kemenkes, 2013). Perbedaan ini terjadi karenalansia yang tadinya berasal dari desa lebih memilih kembali ke desa di hari tuanya namun jumlah lansia yg lebih banyak di tinggal di desa berbanding lurus dengan angka kesakitan lansiadi perdesaan tahun 2008 sampai 2012 dibandingkan dengan lansia di daerah perkotaan, hal ini dapat diartikan bahwa derajat kesehatan lansia yang tinggal di daerah perkotaan relatif lebih baik dibandingkan dengan lansia yang tinggal di perdesaan (13)

Bagi lansia, perubahan peran dalam keluarga, sosial ekonomi, dan sosial masyarakat tersebut mempengaruhi kemunduran dalam beradaptasi dengan lingkungan baru dan berinteraksi dengan lingkungan sosialnya. Perubahan fisik yang terjadi pada Lansia erat kaitannya dengan perubahan psikososialnya. Pengaruh yang muncul akibat berbagai perubahan pada lansia tersebut jika tidak teratasi dengan baik, cenderung akan mempengaruhi kesehatan lansia secara menyeluruh dan mempengaruhi kualitas hidupnya.

Berdasarkan uraian tersebut diatas, penulis tertarik untuk melakukan penelitian tentang "Prediktor faktor lingkungan sosial terhadap kualitas hidup lansia di wilayah Rural dan Urban Kota Cimahi".

\section{METODE}

RANCANGAN PENELITIAN YANG DIGUNAKAN DALAM PENELITIAN INI ADALAH PENELITIAN CROSS SECTIONAL DIMANA PENELITI MENCARI HUBUNGAN ANTARA VARIABEL BEBAS (FAKTOR RISIKO) DENGAN VARIABEL TERGANTUNG (EFEK) DENGAN MELAKUKAN PENGUKURAN SESAAT. 


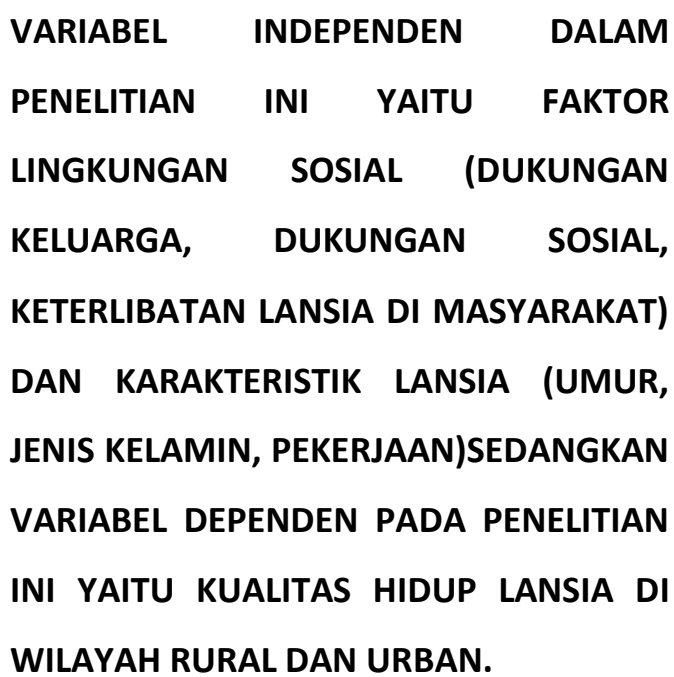

POPULASI DALAM PENELITIAN INI ADALAH LANSIA YANG TINGGAL DIKAWASAN RURAL YAITU DI WILAYAH KERJA PUSKESMAS PASIR LANGU SEBANYAK 3.194 ORANG DAN DI KAWASAN URBAN YAITU DI WILAYAH KERJA PUSKESMAS CIMAHI TENGAH SEBANYAK 2.052 ORANG. UKURAN SAMPEL DIHITUNG DENGAN MENGGUNAKAN METODE SLOVIN DAN DIPEROLAH SAMPEL SEBESAR 94, DAN SELANJUTNYA DITENTUKAN SEBAGAI BESAR SAMPEL UNTUK MASING MASING WILAYAH (RURAL DAN URBAN).

\section{HASIL DAN PEMBAHASAN}

Analisis univariat dilakukan dengan menggunakan uji statistik untuk melihat distribusi dari variabel independen yaitu karakteristik umur lansia.

Tabel 1 Distribusi Frekuensi Demografi Karakteristik Lansia di Wilayah Rural dan Urban

\begin{tabular}{|c|c|c|c|c|c|}
\hline Variabel & $\mathbf{N}$ & Mean & SD & SE & $\begin{array}{c}p \\
\text { value }\end{array}$ \\
\hline \multicolumn{6}{|l|}{ Dukungan } \\
\hline \multicolumn{6}{|l|}{ Sosial } \\
\hline Rural & 98 & 42,60 & D 1,654 & 0,167 & 0,979 \\
\hline Urban & 94 & 42,60 & 1,718 & 0,177 & \\
\hline \multicolumn{6}{|l|}{ Fungsi } \\
\hline \multicolumn{6}{|l|}{ Keluarga } \\
\hline Rural & 98 & 12,73 & 2,250 & 0,227 & 0,376 \\
\hline Urban & 94 & 12,46 & 2,067 & 0,213 & \\
\hline \multicolumn{6}{|l|}{ Keterlibatan } \\
\hline \multirow{2}{*}{\multicolumn{6}{|c|}{$\begin{array}{l}\text { Lansia di } \\
\text { Masyarakat }\end{array}$}} \\
\hline & & & & & \\
\hline Rural & 98 & 10,85 & 1,106 & 0,112 & 0,0001 \\
\hline Urban & 94 & 11,51 & 0,800 & 0,082 & \\
\hline \multicolumn{6}{|l|}{ Kualitas } \\
\hline \multicolumn{6}{|l|}{ Hidup Lansia } \\
\hline \multicolumn{6}{|l|}{ Rural } \\
\hline & 98 & 77,22 & 5,351 & 0,540 & 0,0001 \\
\hline Urban & 94 & 79,93 & 3,093 & 0,525 & \\
\hline
\end{tabular}

Berdasarkan tabel 1, Wilayah Rural sebagian besar adalah lansia muda sebanyak $54(55,1 \%)$ responden, pada variabel jenis kelamin diperoleh bahwa sebagian besar jenis kelamin lansia adalah perempuan yaitu $76(77,6 \%)$ responden.

Tabel 2 hubungan bivariate antar variabel

\begin{tabular}{lll}
\hline Variables & $\begin{array}{l}\text { coefficient } \\
\text { correlation }\end{array}$ & $\mathrm{p}$ value \\
\hline Umur & .014 & .846 \\
Dukungan Sosial & -.112 & .123 \\
Fungsi keluarga & $.200^{* *}$ & .005 \\
Keterlibatan & $.180^{*}$ & .013 \\
lansia di & & \\
masyarajat & & \\
\hline
\end{tabular}

Bedasarkan table diatas peneliti menetapkan bahwa variable jenis kelamin, umur, dukungan social (ISEL) Peran keluarga (APGAR), dan keterlibatan 
dalam aktifitas social (SCREAM) sebegai model predictor dalam pemodelan. Namun, umur dan jenis kelamin tetap dimasukkan kedalam model karena pertimbangan sebagai variable control.

Tabel 3. Model prediktor kualitas hidup lansia

\begin{tabular}{|c|c|c|c|c|c|c|}
\hline \multirow[t]{3}{*}{$\begin{array}{l}\text { Variable } \\
\text { s }\end{array}$} & \multicolumn{3}{|c|}{$\begin{array}{c}\text { Urban Model } \\
\mathrm{R}=0.17, \mathrm{p}= \\
0.014 \\
\text { Standardized } \\
\text { Coefficients }\end{array}$} & \multicolumn{3}{|c|}{$\begin{array}{c}\text { Rural Model, } \\
\mathrm{R}=0.056, \mathrm{p}= \\
0.399 \\
\text { Standardized } \\
\text { Coefficients }\end{array}$} \\
\hline & \multirow[b]{2}{*}{ B } & \multirow{2}{*}{$\begin{array}{l}\mathrm{Be} \\
\text { ta }\end{array}$} & \multirow[t]{2}{*}{ Sig } & & $\mathrm{Be}$ & \\
\hline & & & & $B$ & ta & Sig. \\
\hline (Consta & 68.2 & & .00 & 52. & & \\
\hline nt) & 66 & & 0 & 743 & & .000 \\
\hline & & .03 & .73 & .01 & .0 & \\
\hline Umur & .024 & 5 & 7 & 9 & 31 & .778 \\
\hline Jenis & & .02 & .78 & 1.7 & .1 & \\
\hline Kelamin & .312 & 9 & 3 & 58 & 76 & .114 \\
\hline Dukung & & - & & - & - & \\
\hline an & - & .20 & .04 & .14 & .0 & \\
\hline Sosial & .548 & 2 & 2 & 5 & 63 & .548 \\
\hline $\begin{array}{l}\text { Dukung } \\
\text { an }\end{array}$ & & & & & & \\
\hline Keluarg & & .36 & .00 & .26 & .1 & \\
\hline a & .738 & 9 & 0 & 1 & 36 & .215 \\
\hline $\begin{array}{l}\text { Keterlib } \\
\text { atan } \\
\text { Lansia di }\end{array}$ & & & & & & \\
\hline Masyara & & .07 & .47 & .77 & .1 & \\
\hline kat & .285 & 0 & 1 & 1 & 56 & .157 \\
\hline
\end{tabular}

Hasil uji pemodelan dengan variable yang telah terpilih menunjukkan bahwa pemodelan tidak signifikan untuk diterapkan pada populasi lansia di wilayah rural. Sedangkan kuaitas hidup lansia di wilayah urban secara signifikan diperngaruhi oleh dukungan social dan dukungan keluarga sebesar $17 \%$. Faktor lainnya kemungkinan mempengaruhi kualitas hidup lansia tidak dikaji dalam penelitian ini.

Model yang dikonstruksikan oleh peneliti yang etrdiri dari dukungan keluarga, dukungan social dan peran lansia di komunitas, tidak sesuai untuk lansia yang tinggal di wilayah urban, diperlukan pemodelan lain yang sesuai untuk mendeskripsikan kualitas hidup lansia di wilayah rural. Sedangkan untuk lansia di wilayah urban model yang dibuat telah secara signifikan mempengaruhi kualitas hidup lansia dengan koefisien korelasi sebesar $17 \%$ dimana variable dominan yang mempengaruhi adalah fungsi keluarga dan keterlibatan lansia di masyarakat.

Fungsi keluarga menjadi variabel dominan dikarenakan fungsi keluarga adalah sebuah proses yang terjadi sepanjang masa kehidupan (14). Fungsi keluarga merupakan menjadi informasi verbal maupun nonverbal, saran, bantuan, atau tingkah laku yang diberikan oleh orang orang terdekat berupa kehadiran serta hal-hal yang dapat memberikan keuntungan emosional kepada penerimanya (15). Hasil penelitian ini juga didukung oleh hasil penelitian Penelitian lain menyatakan bahwa fungsi keluarga 
mempengauhi kualitas hidup lansia fungsi keluarga yang baik dari keluarganya(16). Menurut teori individu yang mendapatkan fungsi keluarga yang kuat lebih cenderung kualitas hidupnya tinggi.

Keterbatasan dari penelitian ini adalah tidak ada nilai hasil dari tiap domain pada kuesioner dukungan keluarga, sehingga tidak diketahui domain mana yang paling berpengaruh pada kualitas hidup lansia secara keseluruhan.Instrumen penelitian yang berupa kuesioner memungkinkan bersifat subjektif, sehingga kebenaran data sangat tergantung pada kejujuran serta pemahaman lansia.

Pada penelitian ini keterlibatan lansia di masyarakat yang memiliki skor minimum 8 dan skor maksimum 18 serta mean 11,7. Pada pemodelan akhir uji regresi linier ganda faktor lingkungan sosial yang berhubungan dengan kualitas hidup lansia di wilayah urban adalah variebel fungsi keluarga dan keterlibatan lansia di masyarakat menjadi varibel dominan. Keterlibatan lansia di masyarakat menjadi variabel dominan karena keterlibatan lansia di masyarakat merupakan proses yang direncanakan dengan tujuan khusus yaitu bekerja dengan kelompok, menjadikan lansia terhubung oleh lokasi geografis, minat khusus atau mengidentifikasi untuk mengatasi masalah yang mempengaruhi kesejahteraan Lansia.

Penelitian yang dilakukan sebelumnya menunjukkan bahwa, lansia dengan keterlibatan sosial yang lebih besar memiliki semangat dan kepuasan hidup yang tinggi dan penyesuaian serta kesehatan mental yang lebih positif dari pada lansia yang kurang terlibat secara social(17). Semangat dan kepuasan hidup yang dialami lansia menyebabkan kualitas hidupnya membaik, hal ini yang menjelaskan bahwa lansia yang memiliki hubungan sosial baik sebagian besar adalah lansia yang memiliki kualitas hidup yang baik pula. Individu yang mengalami hubungan sosial yang terbatas dengan lingkungan sekitarnya lebih berpeluang mengalami kesepian, sementara individu yang mengalami hubungan sosial baik tidak terlalu mengalami kesepian yang berarti kualitas hidupnya baik.

Dari penjelasan diatas menurut peneliti lansia yang memiliki hubungan sosial baik adalah lansia yang memiliki kualitas hidup yang cukup baik pula begitu juga dengan lansia yang memiliki hubungan sosial buruk memiliki kualitas hidup yang rendah karena lansia menarik diri dari lingkungan sekitarnya dan itu berakibat berkurangnya kualitas hidup lansia karena lansia dengan keterlibatan sosial yang lebih besar 
memiliki semangat dan kepuasan hidup yang tinggi dan penyesuaian serta kesehatan mental yang lebih positif dari pada lansia yang kurang terlibat secara sosial. Semangat dan kepuasan hidup yang dialami lansia menyebabkan kualitas hidupnya membaik.

Penelitian ini tidak mengidentifikasi secara keseluruhan varibel yang dapat mempengaruhi kualitas hidup lansia, melainkan hanya focus pada lingkungan social. Sehingga seceraa keseluruhan kualitas hidup lansia tidka dapat diidentifikasi prediktor - prediktornya. Penelitian lebih lanjut diperlukan untuk mengidentifikasi prediktor kualotas hidup lansia secara keseluruhan.

Penelitian ini terlaksana berkat dukungan Hibah Penelitian dari Universitas Respati Indonesia tahun anggaran 2018/2019.

\section{Daftar Pustaka}

1. UNDESA (United Nation for Departement of Economic and Social Affair). World Population Prospect 2019. New York, USA; 2019.

2. BPS (Badan Pusat Statistik). Kabupaten Bandung barat dalam Angka (Statistic of Bandung Regency). Bandung; 2018.

3. Kementerian Badan Penelitian dan
Pengembangan Kesehatan. HASIL UTAMA RISKESDAS 2018

Kesehatan. 2018;20-1.

4. Kementrian Kesehatan RI (Ministry of Health Republic Indonesia). Situasi lanjut usia 2016 (Elderly Situation of 2016). 2016;1.

5. Nuraini K, Haryanto J, Fauzingtyas R. Lansia Dengan Diabetes Mellitus Di Wilayah Kerja Puskesmas Bantul 1 Yogyakarta. 2017;4(2):171-8.

6. Rohmah AIN, Purwaningsih $P$, Bariyah K. Quality of Life Elderly. Keperawatan. 2012;3(2):120-32.

7. Herrera Ponce MS, Barros Lezaeta C, Fernández Lorca MB. Predictors of Quality of Life in Old Age: A Multivariate Study in Chile. J Popul Ageing. 2011;4(3):121-39.

8. Setiati S, Harimurti K, Dewiasty E, Istanti R. Predictors and scoring system for health-related quality of life in an Indonesian community-dwelling elderly population. Acta Med Indones. 2011;43(4):237-42.

9. Wongsawat S. Predicting Factors for Quality of Life of Elderly in the Rural Area. Int J Art Sci. 2017;09(04):363-71. 
10. Palompon DR, Ong M. Predictors of Quality of Life of Institutionalized and Community Dwelling Elderly. CNU J High Educ. 2015;9:152-61.

11. Ellulu MS. Osong Public Health and Research Perspectives The Interrelationships and the Determinants among Adults in Gaza City, Palestine. 2018;9(6):289-98.

12. Adioetomo SM, Mujahid G. Indonesia on the Threshold of Population Ageing. 1st ed. Posselt Horst, editor. Vol. 1, UNFPA Indonesia Monograph Series. 2014. $90 \mathrm{p}$.

13. Riskesdes. Riskesdas 2018 (National Basic Health Reserach 2018). Kementrian Kesehatan Republik Indonesia (Ministry of Helath Republic Indonesia). Jakarta; 2018.

14. Subpraba S. Hubungan Aktivitas Sosial, Interaksi Sosial dan Fungsi
Keluarga Dengan Kualitas Hidup Lansia di Wilayah Kerja Puskesmas I Denpasar. UNiversitas Udayana; 2015.

15. Fitriyadewi LPW, Suarya LMKS. Peran Interaksi Sosial Terhadap Kepuasan Hidup Lanjut Usia. J Psikol Udayana. 2016;3(2):332-41.

16. Sutikno E. Hubungan Antara Fungsi Keluarga dan Kualitas Hidup Lansia. Universitas Sebelas Maret; 2011.

17. Chippendale T, Boltz M. The neighborhood environment: Perceived fall risk, resources, and strategies for fall prevention. Gerontologist. 2015;55(4):575-83. 